\title{
Sexual Harassment at Workplace and its Impact on Employee Turnover Intentions
}

\begin{abstract}
Maheen Salman ${ }^{1}$, Fahad Abdullah², Afia Saleem ${ }^{3}$
Abstract

This paper attempts to investigate the impact of sexual harassment on employee turnover intention in educational sector of Peshawar, Pakistan. A total of 127 respondents are selected from 3 public and 3 private sector business schools of Peshawar. Using simple linear regression, the results reveal the existence of positive relationship between sexual harassment and employee turnover intentions. The research suggests strong interventions to reduce the incidents of sexual harassment in order to retain employees and enable them to work efficiently.
\end{abstract}

Keywords: Sexual harassment, turnover intention

\section{Introduction}

In developing countries such as Pakistan, difficulties for women seem to be never ending. At present, where women pass through the realms of practical life and the world can at last rejoice the presence of a law against sexual harassment $(\mathrm{SH})$ at workplace in force, the vulnerability of females to this repugnant offense has increased manifold (Sadruddin, 2013). This is primarily because women are embracing practical life more than ever and are largely a step ahead of males in their pursuit of higher education. Moreover, the patriarchal system, being our predominant social setup, which not only limits men to engage in inhuman and immoral acts against women but also grants them the privilege to flagrantly refute the prevalence of these prejudices that almost every woman experiences at some point in her life. Speaking particularly about the workplace harassment, even if victims realize that they are being harassed, they lack the resources and the confidence to stand against different forms of sexual harassment occurrences they go through (Sadruddin, 2013). In a conservative and male dominated society such as Peshawar, women tend to remain silent on the prejudices they face because they fear that their image in the society will be ruined and that their own family will discourage them from working in organizations (Mernissi, 1987). According to Parveen (2010), a total 24119 of violence against women cases were

1 PrincipalAuthor:BBA student, Institute of Management Sciences, Pakistan, Email address: maheen.15@hotmail.com

2 Co-Author:Assistant Professor, Institute of Management Sciences, Pakistan, Email address: fahad. abdullah@imsciences.edu.pk

3 Co-Author:Lecturer, Institute of Management Sciences, Pakistan, Email address: afiaSaleem@ yahoo.com 
reported in Pakistan during 2008-10 of which only 520 workplace harassment cases were filed. This augments the vulnerability of women to this obnoxious crime even more. Unfortunately, the incidents of sexual harassment, particularly at workplace, are multiplying with every passing day without any improvement, even though the law against these acts exists (Yousaf \& Schmiede, 2016).

There are hardly any researches in the context of Pakistan that raise voice against the prevalence of sexual harassment at workplace and its consequences for employee turnover intentions. Most of the researches on this topic are conducted either in corporate sector or in hospitals. However, little attention is given in this regard in the educational sector. Considering this, the present study aims to investigate the gravity and intensity of sexual harassment pertinent to employees of business schools belonging to Peshawar. It attempts to know employees' intentions with regards to leaving their workplace due to their exposure to harassment provoking environment.

\section{Literature Review}

Although the concept of sexual harassment is an old one (Thornton, 2002), it was acknowledged as a socio-legal phenomenon in recent times, coming to the limelight partly due to the rise of radical feminist movements sprouting in the US (MacKinnon, 1979). Empirical researches in Europe also exhibited that majority of women experience sexual harassment at their workplace, thus bringing the issue to the knowledge of general public (MacKinnon, 1979; Rubinstein, 1987) where it soon became focus of attention for women's activist movements and equality of employment opportunity discourse, and shortly afterwards transformed into laws and practices in distinctive social, political and legal contexts worldwide (Zippel, 2006).Sexual harassment has been recognized and addressed at international level by various organizations including the International Confederation of Free Trade Unions, International Labour Organization, the United Nations Committee on the Elimination of Discrimination against Women, and the European Union. To confront the challenge, associations and organizations have formulated policies and introduced mutually agreed clauses, provided direction to abide by the laws, organized trainings, and introduced procedures with regards to filling SH complaints (McCann, 2005). Sexual harassment is considered as one of the counterproductive behaviors at workplace and can take many forms. Such behaviors include racial harassment, mobbing, general bullying, passing insulting comments, offensive remarks, and marginalizing behaviors on grounds of gender (Thornton, 2002; Zippel,2006).

\subsection{Defining Sexual Harassment}

The definition of sexual harassment has stayed under discussion for so many 
years till date. The reason behind this is variation of discernments and perceptions in societies. In few societies, acts performed under sexual harassment such as flirting can be considered as pleasant for creating fun among the work groups; though it is unacceptable in other societies (Nauman \& Abbasi, 2014). There is no universally agreed definition of sexual harassment; however, a large number of definitions incorporate similar components, e.g. describing a behavior as unwelcome or unwanted which has the qualities of being hostile, insulting, offensive, or intimidating (McDonald, 2012). Distinction between unwanted sexual advances and comments that may be considered inappropriate is often puzzled. Inappropriate comments and remarks do not fall under the umbrella of sexual harassment most commonly but according to Equal Rights Advocates, Inc. (2013), if such minor incidents are frequently being experienced and affect the work, then it is categorized as sexual harassment. Furthermore, there is no limitation as to where sexual harassment can take place. Be that place a work environment or any other place (such as religious madrassas, schools, offices, hospitals), incidents of sexual harassment can occur. However, for the purpose of this study, sexual harassment at business schools of Peshawar is considered. United Nations characterizes harassment as a sort of conduct (verbal or physical) which prevents work or advance hostile behavior at workplace (UN, n.d.). A standout amongst the most widely recognized forms of harassment is the one characterized as unethical behavior which a person finds debilitating or hostile (Goonesekere, 2004). This unwelcome and unwanted conduct is part of all occupations and work environments, though kept as secret, making it a concealing phenomenon (Hunt, Davidson, Fielden, \& Hoel, 2007). It can take many forms, e.g. gender harassment (abusive behavior verbal/ nonverbal), sexual coercion (offering bribes or threatening), or indulging in unethical behaviors to seek attention (calling, touching) (Fitzgerald, Gelfand, \& Drasgow, 1995). The topic of sexual harassment is so vast and broad that it is difficult to label a particular behavior as incident of sexual harassment. It has different types ranging from conducts purely sexual in nature to the ones that are unwelcome that make work environment uncomfortable. EEOC classifies sexual harassment under two broad categories, namely hostile environment, and quid pro quo harassment. The most commonly recognized type of sexual harassment, "quid pro quo", comes from a Latin terminology which literally means "this for that". When a person submits to or refuses the immoral requests of the harasser and such requests are made for the employment decisions affecting the harassed individual, this is termed as a quid pro quo harassment (Notice of Policy Guidance, 1990). Failure to comply with harasser's requests or offers causes an adverse impact on employment procedures such as promotion, compensation and benefits, performance appraisals, and other conditions.

Hostile environment is a kind of sexual harassment that gives rise to an intimidating, hostile, or offensive work environment (Equal Rights Advocates, Inc., 2013). 
Victims' response to stop sexual harassment behaviors will adversely affect the conducts of their job. Examples of acts that make an environment hostile include demotion, denied employment, and in extreme cases this may result in termination and poor performance on the job as a result of mental and emotional stress instigated by such environment.

However, it should be noted that both categories of sexual harassment can occur simultaneously. Therefore, an explicit distinction between the two has remained an ambiguous phenomenon. Both categories can share similarities in situations where the supervisor abuses his authority over employment decisions to force the victim to endure or participate in the sexual conduct (Notice of Policy Guidance, 1990). Furthermore, retaliation may also occur if the supervisor terminates his employee due to the latter's denunciation of repeated abuse.

Since there is no universally agreed definition of sexual harassment, therefore, for this research paper, the definition will comprise of descriptions of the conduct being unwelcome or unwanted, and which has the drive or effect of being hostile, intimidating, offensive, or humiliating, as these are the most commonly experienced acts of sexual harassment.

\subsection{Concept of Sexual Harassment in the Context of Pakistan}

Compared with the Western World, Pakistan's religious, economic, and socio-cultural constructs and contexts differ considerably (Syed, 2008). To give respect, protection, and equal rights to women are some of the provisions that are clearly mentioned in both the religion and the Constitution of Pakistan. Nevertheless, Pakistan continues to be a society where male dominancy is deeply engraved in all regions and cultures, making it difficult for women to attain their rights (Akhtar \& Métraux, 2013). Despite the fact that sexual harassment is not explicitly and well defined in Pakistan, it encompasses several brutal instances against women, for example acid attacks, honor killings, domestic violence, burning, rape, denial of property, trafficking for forced labor and sex, early marriages, torture, obscene/threatening phone calls, exchange of females to resolve disputes, and even selling them to get rid of poverty (Nosheen, 2011). In certain instances, women are unfortunately victimized and suppressed by their own family members (Akhtar \& Métraux, 2013; Nosheen 2011). Despite so many amendments in the constitution of Pakistan, the state failed to improve and augment economic and political rights intended for women. Not only this, the state also fell short to apply its own laws to protect them (Akhtar \& Métraux, 2013; Nosheen, 2011; Qureshi, 2013). In fact, the law enforcement agencies, such as police itself is a threat to the security of women in Pakistan. It is a common practice here that women are victimized and harassed by police (Abbas, 2011). Furthermore, politicians, particularly females, who 
did efforts to raise their voice against anti-feminist forces and fundamentalists, have been put to their death beds. The assassination of Benazir Bhutto is a clear example of it (Hall, 2011). In the education sector, the Higher Education Commission (HEC) of Pakistan made it mandatory for higher educational institutes and universities to implement the HEC policy guidelines to prevent sexual harassment; but according to HEC, more than $80 \%$ of the universities of Pakistan have not implemented the law (Yousaf \& Schmiede, 2016). According to Dawn News (2011), the University of Peshawar's management did not even know whether HEC policy guidelines on sexual harassment exist. With the rise in influx of women to the workforce of Pakistan, phenomenon of sexual harassment has come to the limelight and thus gained attention of researchers (Saeed, 2012). Pakistan is a country with Muslim majority population characterized by patriarchal society with gender segregation (Yasin, Chaudhry, \& Afzal, 2010). Despite the efforts of Government regarding the spreading of basic education to all citizens indiscriminately (Latif, 2009), a large number of females are mostly kept inside home or work somewhere at a very low paid job instead of going to schools (Desai, 1994; Nosheen, 2011). An increase in the usage of television, access to internet, and awareness schemes by non-governmental organizations (NGO's) have significantly enlightened women about their rights and how to speak up for their rights. Along with that, globalization and western culture has played a tremendous role increasing interest and drive in women to seek employment which is contrary to the traditional principles of a male dominant culture supported by dismayed fundamentalists (Mernissi, 1987). Contrary to the beliefs of these fundamentalist groups is the real teachings of Islam, which permits women to work outside their home and seek jobs which fit their nature, particularly when she or her family needs support (Hifazatullah, Badshah, Muhammad, Farooq, \& Khan, 2011).

Despite the efforts made by the state of Pakistan to make education accessible for females, obstacles such as male dominancy, paternalistic culture, and insufficient legal protection from sexual harassment hinder women's involvement in the labor force (Raza, 2007). To achieve sustainable economic growth and development, Pakistan needs increased participation of women in the aggregate labor force of the country (Qureshi, Khan, \& UlHussain, 2007). Therefore, it is viable to know the relationship of sexual harassment and turnover intention in a male dominant society of Peshawar.

In addition to this, it is found that turnover costs are the major contributor to the total cost of sexual harassment (Faley, Knapp, Kustsi, \& DuBois, 1994). Turnover intention has a negative relation with job satisfaction (e.g., Amah, 2009). Since sexual harassment lowers job satisfaction, it will increase the turnover intention (Merkin, 2008). If the dependency ratio of employees on other employees is high, then the turnover costs tremendously increase. In most of the cases, the turnover intention 
eventually leads to actual turnover, as demonstrated through the meta-analyses by Steel and Ovalle (1984), and former studies which conclude that turnover intentions are the strongest predictor of turnover (Mobley, Horner, \& Hollingsworth, 1978). Based on these arguments, the study proposes the following hypothesis.

$\mathrm{H}_{1}=$ There is a significant relationship between sexual harassment and employee turnover intentions

Regardless of the sector, wherever women work, incidents of workplace harassment or sexual harassment occur. Majority of the studies on sexual harassment all over the world, and specifically in Pakistan, are geared towards sexual harassment faced by women. Reason for this are the existence of patriarchal values deep rooted in Asian societies. A report by World Bank (1993) also elicits that one woman out of every three across the world has experienced and endured violence at some point in her life in one way or the other. Therefore, the reports of sufferings faced by women served as a motivation behind this study.

\section{Methodology}

This research intends to test the impact of sexual harassment and its relationship with employee turnover intentions. For this purpose, data from 126 respondents is collected from business schools of Peshawar, using SEQ and Mobley's Turnover intention questionnaire (see the attachment at Appendix-A).

\subsection{Population and Sampling}

The study selects a random sample of six business management universities of Peshawar from the HEC's list of universities, three from each Public and Private sector. Faculty members of the sampled universities were given the questionnaires for the purpose of data collection. Using this sampling technique, the total sample accounted for 126 people, out of which 44 were females and 82 were males.

\subsection{Measurement and Data Collection}

To measure sexual harassment, the well-known instrument named Sexual Experiences Questionnaire (SEQ) of Fitzgerald et al. (1995) is used. It is known for having best psychometric properties. It is comprised of 17 questions, assessing the frequency of sexual harassment experienced by males and female workers. These 17 questions cover 3 major types of harassment including gender harassment (any behavior/s that expresses degrading, insulting, sexist remarks about opposite gender), unwanted sexual attention (stroking, touching, repeated requests for sexual or romantic relationship), and coercion (any behavior that is threatening or frighten co-workers to cooperate, 
else they will be ill-treated, or offering bribe for sexual advances). To measure the frequency of sexual harassment, a 5 -point scale was adopted with values $1=$ Never, $2=$ Once, 3 = Sometimes, 4 =Often, $5=$ Most of the time.

To measure turnover intentions, standard instrument of Mobley's Turnover Intention Questionnaire was used. It comprises of 3 questions predicting turnover intentions on a 5 point Likert scale with values $1=$ Strongly Disagree, $2=$ Disagree, $3=$ Neutral, 4= Agree, 5= Strongly Disagree.

Using both the valid and pre-tested instruments, questionnaire for this study was categorized into two sections. Section 1 targeted the demographics (Gender, Age, Marital status and rank) whereas Section 2 was an amalgam of SEQ and Mobley's Turnover Intention Instrument.

\section{Analysis and Results}

\subsection{Reliability of the Instrument}

Table 1 presents the reliability test for each of the scales utilized in the study.

Table 1: Reliability of the Instrument

\begin{tabular}{|c|c|c|}
\hline & Number of items & Cronbach Alpha \\
\hline SEQ (Sexual Harassment Questionnaire) & 17 & 0.941 \\
\hline TOI (Turn Over Intention Questionnaire) & 3 & 0.911 \\
\hline
\end{tabular}

${ }^{*} \alpha \geq 0.6$.

For an instrument to be considered reliable, the value of Cronbach's alpha should at least be 0.6 (Santos, 1999). The reliability test of both the instruments is greater than 0.6 as depicted in Table 1 above. Hence, both the instruments are interpreted as reliable.

\subsection{Demographic Profiles of the Respondents}

Table 2 presents the profiles of the respondents.

According to the data presented in Table 2 , it is evident that the majority of respondents of the study are males as shown from their percentage, i.e. $65 \%$. The rest $35 \%$ are females. The table also shows that $64 \%$ of the respondents fall in the age group ranging from 25 years to 35 years. $57.1 \%$ of the respondents are married and majority of them are designated as Lecturer and Assistant Professors. 
Table 2: Demographic Profiles of the Respondents

\begin{tabular}{|c|c|c|c|}
\hline & MEAN & \multicolumn{2}{|c|}{ FREQUENCY (\%) } \\
\hline Gender & 1.3492 & Male & 65 \\
\hline & & Female & 35 \\
\hline Age & 1.4841 & $25-35$ & 64.3 \\
\hline & & $36-45$ & 26.2 \\
\hline & & $46-55$ & 6.3 \\
\hline & & 55 and above & 3.2 \\
\hline Marital Status & 1.4286 & Single & 42.9 \\
\hline & & Married & 57.1 \\
\hline Rank & 1.7302 & Lecturer & 57.1 \\
\hline & & Assistant Professor & 23.8 \\
\hline & & Associate Professor & 7.9 \\
\hline & & Professor & 11.1 \\
\hline
\end{tabular}

Source: Survey data, 2015

\subsection{Regression Results}

Numerous researches advocate that sexual harassment is positively associated with employee turnover intentions. Therefore, this research further tests the relationship between sexual harassment and employee turnover intentions in the context of Peshawar, Pakistan. The following hypothesis was posed for this study earlier:

$\mathrm{H}_{1}=$ There is a positive relationship between sexual harassment and employee turnover intentions

Table 3 presents the results of the regression analysis.

Table 3: Results of Regression Analysis

\begin{tabular}{|c|c|c|c|c|c|c|c|c|}
\hline Model & $\mathrm{R}$ & $\begin{array}{c}\mathrm{R} \\
\text { Square }\end{array}$ & $\begin{array}{c}\text { Adjusted } \\
\mathrm{R}^{2}\end{array}$ & $\mathrm{~F}$ & $\begin{array}{c}\text { Sig } \\
(\mathrm{P} \leq 0.05)\end{array}$ & $\begin{array}{c}\text { Standardized } \\
\text { Coefficients }(\beta)\end{array}$ & $\mathrm{T}$ & $\begin{array}{c}\text { Sig } \\
(\mathrm{P} \leq 0.05)\end{array}$ \\
\hline 1 & 0.546 & 0.299 & 0.293 & 51.101 & .000 & 0.546 & 7.148 & .000 \\
\hline
\end{tabular}

$\mathrm{P}=\leq 0.05$

The value of $\mathrm{R}$ square shows that $29 \%$ of the variation in the dependent variable (employee turnover intention) is explained by the independent variable (sexual harassment). The model is highly significant at $(\mathrm{F}=51.101, p=.000)$ which shows that it can be used to predict the outcome variable. The value of coefficient $(\beta=0.546)$ is significant and positive, showing that sexual harassment leads to increased turnover of employees. Hence on the basis of the aforementioned findings, $\mathrm{H}_{0}$ proves to be false, 
affirming that there is a significant positive relationship between sexual harassment and employee turnover intentions.

\section{Conclusion and Recommendations}

The results of the study explicitly show that sexual harassment does lead to employee turnover intentions. Despite the fact that Pakistani population is reluctant to reveal their sexual harassment experiences, results proved that sexual harassment increases employees' turnover ratio. Consequently, the employer has to bear enormous costs of turnover which are the major contributor to the total cost of sexual harassment (Faley et al. 1994). Furthermore, turnover intention has a negative relationship with job satisfaction (e.g., Amah 2009). Since sexual harassment decreases job satisfaction and increases turnover intention, therefore, hypothesis posed for this study that sexual harassment increases turnover intention proves to be true. Employers should reduce incidents of sexual harassment as it will ultimately lead to tremendous turnover costs to bear in future.

This research also highlights the bitter reality of higher educational institutes that failed to implement the guidelines of HEC on sexual harassment. Aforementioned discussion enhances the importance of this study. In this era of global competition, it is highly important for the employers to know the reasons behind their employee turnover intentions and actual turnover, so that employee retention strategies can rightly be devised and the crime of sexual harassment can be reduced substantially.

\subsection{Implications for Future Research}

Future researches should focus on qualitative methodology in order to obtain an in-depth view of the most common type of harassment faced. As it is clear from this research that sexual harassment significantly affects employee turnover intentions, a further step should be taken to exactly find out what are the most common types of sexual harassment faced by employees. This will help in many ways, particularly when devising intervention models. Moreover, future researches should consider previously untapped segments of people such as students, maids or servants at home, and students in madrassas that are vulnerable to harassment. A longitudinal study is also recommended for future researches in which data should be collected from the same respondents over a long time period so that a valuable insight about the trends and changes in the perception of sexual harassment can be uncovered.

\section{References}

Abbas, H. (2011). Reforming Pakistan's police and law enforcement infrastructure. US Institute of Peace, Washington, DC. 
Akhtar, N., \& Métraux, D. A. (2013). Pakistan is a dangerous and insecure place for women. International Journal of World Peace, 30(2), 35-70.

Amah, O. E. (2009). Job satisfaction and turnover intention relationship: the moderating effect of job role centrality and life satisfaction. Research Practices in Human Resource Management, 17(1), 24-35.

Dawn News (2011). http://www.dawn.com/news/630267/sexual-harassment-on-campus universities-oblivious-of-hec-guidelines.

Desai, S. (1994). Gender inequalities and demographic behavior. The Population Council: New York.

Goonesekere, S. (2004). Violence, law and women's rights in South Asia. India: SAGE Publications.

Faley, R. H., Knapp, D. E., Kustsi, G. A., \& DuBois, C. Z. (1994).Organizational costs of sexual harassment in the workplace: The case of the U.S. Army. Presented at the Ninth Annual Conference of the Society of Industrial and Organizational Psychology. Nashville, TN.

Fitzgerald, L. F., Gelfand, M. J., \& Drasgow, F. (1995). Measuring sexual harassment: Theoretical and psychometric advances. Basic and Applied Social Psychology, 17(4), 425-445.

Hall, L. (2011). Call me abar or call me eve: Redefining the female gender. Authorhouse, Bloomington.

Hifazatullah, H., Badshah, N., Muhammad, N., Farooq, H., \& Khan, M. (2011). Attitude of religious concerns towards women emancipation in Tehsil Takht-Bai. Interdisciplinary Journal of Contemporary Research in Business, 3(3), 1135-1154.

Hunt, C., Davidson, M., Fielden, S., \& Hoel, H. (2007). Sexual harassment in the workplace: A literature review. Manchester Business School, University of Manchester.

Equal Rights Advocates, Inc. (2013). Know your rights: Sexual harassment at work. Retrieved from www. equalrights.org/wp-content/uploads/2013/11/KYR_SexHarassWk-v3.pdf

Lakhvi, M., \& Suhaib, A. (2010). Western feminist movement and women protection bill 2006 in Pakistan: An analytical study. Pakistan Journal of Social Sciences, 30(2), 245-250.

Latif, A. (2009). A critical analysis of school enrollment and literacy rates of girls and women in Pakistan. Educational Studies, 45(5), 424-439.

MacKinnon, C. (1979). The sexual harassment of working women. New Haven, CT: Yale University Press.

Mangi, N. (2011). Convoys and pat downs: A day at the office in Pakistan. Bloomberg Businessweek, 4239, $11-13$.

McCann, D. (2005). Sexual harassment at work: National and international responses. Geneva: International Labour Office.

McDonald, P. (2012). Workplace sexual harassment 30 years on: A review of the literature. International Journal of Management Reviews, 14(1), 1-17. 
Merkin, R. S. (2008). The impact of sexual harassment on turnover intentions, absenteeism, and job satisfaction: Findings from Argentina, Brazil and Chile. Journal of International Women's Studies, 10(2), 73-91.

Mernissi, F. (1987). Beyond the veil: Male-female dynamics in modern Muslim society (Vol. 423). Indiana University Press.

Mobley, W. H., Horner, S. O., \& Hollingsworth, A. T. (1978). An evaluation of precursors of hospital employee turnover. Journal of Applied Psychology, 63(4), 408-414.

Nauman, B., \& Abbasi, A. S. (2014). Sexual harassment at workplace: A case of banking sector in Lahore. Middle-East Journal of Scientific Research, 20(5), 558-566.

Nosheen, H. (2011). Violence against women. Dialogue, 6(3), 290-299.

Notice of Policy Guidance. (19 March 1990). EEOC. Number N-915-050. Retrieved from: http://www. eeoc.gov/policy/docs/currentissues.html

Noureen, G., \& Awan, R. (2011). Women's education in Pakistan: Hidden fences on open frontiers. Asian Social Sciences, 7(2), 79-87.

Parveen, R. (2010). Violence against women in Pakistan. Islamabad: Aurat Foundation.

Qureshi, S. (2013). The emergence/extension of due diligence standard to assess the state response towards violence against women/domestic violence. South Asian Studies, 28(1), 55-66.

Qureshi, S., Khan, M., \& UlHusnain, M. (2007). Gender, environment, and sustainable economic growth. Pakistan Development Review, 46(4), 883-892.

Raza, F. (2007). Reasons for the lack of women's participation in Pakistan's workforce. Journal of Middle East Women Studies, 3(3), 99-102.

Rubinstein, M. (1987). The Dignity of Women at Work: A Report on the Problems of Sexual Harassment in the Member States of the European Community. COMV/412/87.

Sadruddin, M. M. (2013). Sexual harassment at workplace in Pakistan-Issues and remedies about the global issue at managerial sector. Journal of Managerial Sciences, 3(1), 1-114.

Saeed, F. (2012). Working with sharks: Countering sexual harassment in our lives. Lahore: Sanjh Publications.

Santos, J. R. A. (1999). Cronbach's alpha: A tool for assessing the reliability of scales. Journal of Extension, 37(2), 1-5.

Schultz, Vicki. (2003). The Sanitized Workplace. Yale Law Journal, 112, 2061-2193.

Steel, R. P., \& Ovalle, N. K. (1984). A review and meta-analysis of research on the relationship between behavioral intentions and employee turnover. Journal of Applied Psychology, 69(4), 673 -686. 
Syed, J. (2008). A context-specific perspective of equal employment opportunity in Islamic societies. Asia Pacific Journal of Management, 25(1), 135-151.

Thornton, M. (2002). Sexual harassment losing sight of sex discrimination. Melbourne University Law Review, 26(2), 422-444.

World Bank. (1993). Investing in Health. New York: Oxford University Press. http://www.equalrights. org/wp-content/uploads/2013/04/KYR_SexHarassSch.pdf

Yasin, G., Chaudhry, I., \& Afzal, S.(2010). The determinants of gender wage discrimination in Pakistan: Econometric evidence from Punjab Province. Asian Social Science, 6(11), 239-255.

Yousaf, R., \& Schmiede, R. (2016). Harassment act implementation in higher education institutions. Open Journal of Leadership, 5(1), 8-19.

Zippel, C. (2006). The politics of sexual harassment. A comparative study of the US, the European Union and Germany. New York: Cambridge University Press. 


\section{Appendix-A}

\section{Research questionnaire:}

\section{Impact of Sexual Harassment on Employee Turnover Intentions in}

\section{Universities of Peshawar}

\section{Dear Participant,}

This questionnaire intends to collect data for academic research only. You are required to fill both the sections of the questionnaire. Your responses will be kept highly confidential.

For your understanding:

The term sexual harassment covers any incidents (physical or verbal) that are intimidating, hostile, degrading, humiliating or offensive that hinders/ negatively affects work. It may not be sexual in nature but threatening.

\section{SECTION 1: DEMOGRAPHICS}

\section{1) Gender:}

1. Male

2. Female

2) Age:

1. $25-35$

2. $36-45$

3. $46-55$

4. $56 \&$ above

3) Marital Status:

1. Married

2. Single

4) Rank:

1. Lecturer 


\section{Assistant Professor}

\section{Associate Professor}

4. Professor

\section{SECTION 2: SEXUAL EXPERIENCES QUESTIONNAIRE (SEQ)}

Please " $\checkmark$ " in the appropriate areas to rate the extent to which you have confronted the below mentioned behaviors at your workplace.

\begin{tabular}{|c|c|c|c|c|c|}
\hline $\begin{array}{r}\text { Have you ever been in a situation where a su- } \\
\text { pervisor/coworker habitually told suggestive } \\
\text { stories or offensive jokes? }\end{array}$ & $\begin{array}{c}1 \\
\text { Never }\end{array}$ & $\begin{array}{c}2 \\
\text { Once }\end{array}$ & $\begin{array}{c}3 \text { Some- } \\
\text { times }\end{array}$ & $\begin{array}{c}4 \\
\text { Often }\end{array}$ & $\begin{array}{c}5 \text { Most of } \\
\text { the time }\end{array}$ \\
\hline $\begin{array}{c}\text { Have you received crude sexual remarks by } \\
\text { your supervisor/coworker? }\end{array}$ & & & & & \\
\hline $\begin{array}{c}\text { Have your supervisor/coworker passed offen- } \\
\text { sive remarks to about you? }\end{array}$ & & & & & \\
\hline $\begin{array}{c}\text { Have you experienced a situation where some- } \\
\text { one displayed offensive materials to you? }\end{array}$ & & & & & \\
\hline $\begin{array}{c}\text { Have you experienced a situation where your } \\
\text { supervisor/coworker passed sexist comments } \\
\text { on you? }\end{array}$ & & & & & \\
\hline $\begin{array}{c}\text { Have you experienced a situation where your } \\
\text { supervisor/coworker attempted to discuss sex } \\
\text { with you? }\end{array}$ & & & & & \\
\hline $\begin{array}{c}\text { Have you ever been in a situation where your } \\
\text { supervisor/co worker tried to gain unwanted } \\
\text { sexual attention? }\end{array}$ & & & & & \\
\hline $\begin{array}{c}\text { Have you experienced a situation where your } \\
\text { supervisor/coworker stared or leered at you? }\end{array}$ & & & & & \\
\hline $\begin{array}{c}\text { Have you experienced a situation where your } \\
\text { supervisor/coworker attempted to establish a } \\
\text { sexual relationship? }\end{array}$ & & & & & \\
\hline $\begin{array}{c}\text { Have you experienced a situation where your } \\
\text { drinks, dinner, despite rejection? } \\
\text { that made you feel uncomfortable? }\end{array}$ & & & & & \\
\hline
\end{tabular}




\begin{tabular}{|c|c|c|c|c|c|}
\hline & $\begin{array}{c}1 \\
\text { Never }\end{array}$ & $\begin{array}{c}2 \\
\text { Once }\end{array}$ & $\begin{array}{l}3 \text { Some- } \\
\text { times }\end{array}$ & $\begin{array}{c}4 \\
\text { Often }\end{array}$ & $\begin{array}{l}5 \text { Most of } \\
\text { the time }\end{array}$ \\
\hline \multicolumn{6}{|l|}{$\begin{array}{c}\text { Have you been in a situation where your } \\
\text { supervisor/coworker made attempts to stroke } \\
\text { or fondle you (e.g. stroking your leg or neck, } \\
\text { etc)? }\end{array}$} \\
\hline \multicolumn{6}{|l|}{$\begin{array}{l}\text { Have you been in a situation where you felt } \\
\text { you were being subtly bribed with some sort } \\
\text { of reward (e.g. preferential treatment) to } \\
\text { engage in sexual behavior with a supervisor/ } \\
\text { coworker? }\end{array}$} \\
\hline \multicolumn{6}{|l|}{$\begin{array}{l}\text { Have you ever been in a situation where } \\
\text { you felt you were being subtly threatened to } \\
\text { engage in sexual behavior with a coworker? }\end{array}$} \\
\hline \multicolumn{6}{|l|}{$\begin{array}{l}\text { Have you ever been in a situation where your } \\
\text { coworker made it necessary for you to cooper- } \\
\text { ate to be treated well? }\end{array}$} \\
\hline \multicolumn{6}{|l|}{$\begin{array}{l}\text { Have you ever been in a situation where you } \\
\text { were made afraid of poor treatment if you } \\
\text { didn't cooperate to engage in sexual behavior } \\
\text { with a supervisor/ coworker? }\end{array}$} \\
\hline $\begin{array}{l}\text { Have you ever been in a situation where you } \\
\text { actually experienced negative consequences } \\
\text { for refusing to engage in sexual activity with a } \\
\text { supervisor or coworker? }\end{array}$ & & & & & \\
\hline \multicolumn{6}{|c|}{$\begin{array}{l}\text { In the context of Harassment Please "ᄆ" in the appropriate areas to rate the extent to which you } \\
\text { think in the following ways: }\end{array}$} \\
\hline & $\begin{array}{l}1 \\
\text { Strong- } \\
\text { ly Dis- } \\
\text { agree }\end{array}$ & $\begin{array}{l}2 \text { Dis- } \\
\text { agree }\end{array}$ & $\begin{array}{l}3 \mathrm{Neu}- \\
\text { tral }\end{array}$ & $\begin{array}{c}4 \\
\text { Agree }\end{array}$ & $\begin{array}{l}5 \text { Strongly } \\
\text { Agree }\end{array}$ \\
\hline \multicolumn{6}{|l|}{$\begin{array}{l}\text { You think a lot about leaving the organiza- } \\
\text { tion? }\end{array}$} \\
\hline \multicolumn{6}{|l|}{$\begin{array}{l}\text { You are actively searching for an alternative to } \\
\text { the organization? }\end{array}$} \\
\hline $\begin{array}{l}\text { As soon as it is possible, You will leave the } \\
\text { organization? }\end{array}$ & & & & & \\
\hline
\end{tabular}


